\title{
REVIEW PEMIKIRAN MODERAT PARA TOKOH ISLAM DALAM BUKU PENDIDIKAN AGAMA ISLAM DAN \\ BUDI PEKERTI
}

\author{
Lilik Huriyah \\ Universitas Islam Negeri Sunan Ampel Surabaya, Indonesia \\ E-mail: lilikhuriyah@uinsby.ac.id \\ Hammis Syafaq \\ Universitas Islam Negeri Sunan Ampel Surabaya, Indonesia \\ E-mail: hamissyafaq@uinsby.ac.id \\ Nasihatul Latifah \\ Universitas Islam Negeri Sunan Ampel Surabaya, Indonesia \\ E-mail: nasi_hatul@yahoo.co.id
}

\begin{abstract}
Nowadays, moderate Islamic thought has been emphasized by the Indonesian government. This can be seen from the school curriculum that includes moderate Islamic thought and tolerance. This study seeks to review moderate Islamic thinking that was initiated by Islamic reformers in the book Pendidikan Agama Islam (PAI) dan Budi Pekerti of class XI Senior High School, that was published by the Ministry of Education and Culture in 2014 and 2017. This article used library research. All data is collected through documentation and analyzed using content analysis. The results of this study stated that in the 2014 edition of the PAI dan Budi Pekerti class XI there was one Islamic figure whose thoughts were extreme and did not include moderate, namely Muhammad b. 'Abd alWahhāb. So that in the 2017 edition of PAI dan Budi Pekerti class XI, the figure of 'Abd al-Wahhāb is no longer presented and replaced with a moderate-minded Islamic figure, namely Namik Kemal. The nine other Islamic figures have moderate Islamic thoughts both in the 2014 and 2017 book edtions.
\end{abstract}

Keywords: Moderate thought; Islamic leaders; Islamic education.

\section{Pendahuluan}

Islam moderat adalah suatu konsep yang akan terus menarik untuk dibahas. Negara-negara dengan penduduk mayoritas ber- 
agama Islam, termasuk Indonesia, tengah berupaya untuk menginternalisasi Islam moderat ke berbagai lini kehidupan. Tak terkecuali dalam hal ini adalah lini pendidikan. Melalui kurikulum di lembaga pendidikan, pemerintah membuat kebijakan agar Islam moderat diinternalisasi ke dalamnya. Di Indonesia, upaya ini sangat terlihat dari kebijakan pemerintah untuk memasukkan materi Islam moderat, pemikiran Islam moderat para tokoh, serta toleransi keberagamaan dalam mata pelajaran seperti Pendidikan Agama Islam dan Budi Pekerti.

Ada banyak penelitian yang telah membahas Islam moderat maupun pemikiran Islam moderat. Taruhlah penelitian Ahmad Ihwanul Muttaqin yang berjudul "Dinamika Islam Moderat: Studi atas Peran LP Ma'arif NU Lumajang dalam Mengatasi Gerakan Radikal." Hadir pula kajian yang membahas tentang Islam moderat konteks Indonesia dalam perspektif historis yang dilakukan oleh Miftahuddin. Islam moderat mengajak untuk memahami Islam secara kontekstual; bahwa perbedaan dan keragaman adalah sunnatullāh yang tidak dapat ditolak keberadaannya; dan Islam adalah agama rabmatan li al-álamin. ${ }^{2}$

Islam moderat sebagai upaya menanggulangi radikalisme di Indonesia juga telah diteliti oleh Eka Prasetiawati. Untuk menanggulangi radikalisme yang bisa berujung pada terorisme, Prasetiawati menegaskan perlunya keterlibatan berbagai pihak, terutama peran lembaga pendidikan. Lembaga pendidikan bisa menanamkan nilai-nilai Islam moderat dengan konsep aswaja: al'adälah (keadilan), al-tawā̃un (keseimbangan), dan al-tasāmub (toleransi). ${ }^{3}$

Sikap moderat antarumat dalam organisasi dan dalam pendidikan juga telah diteliti oleh Malia Fransisca. Kajian literature review Fransisca tersebut menekankan bahwa agar terwujud perdamaian, kerukunan, tiadanya kekerasan, maka sangat dibutuh-

\footnotetext{
${ }^{1}$ Ahmad Ihwanul Muttaqin dan Syaiful Anwar, "Dinamika Islam Moderat, Studi Atas Peran LP. Ma'arif NU Lumajang dalam Mengatasi Gerakan Radikal," Tarbiyatuna: Jurnal Pendidikan Islam, Vol. 12, No. 1 (2019), 20.

2 Miftahuddin, "Islam Moderat Konteks Indonesia dalam Perspektif Historis," MOZAIK, Vol. 5, No. 1 (2010), 41.

3 Eka Prasetyawati, "Menanamkan Islam Moderat: Upaya Menanggulangi Radikalisme di Indonesia," Fikri, Vol. 2, No. 2 (2017), 523.
} 
kan sikap moderat antarumat, baik dalam organisasi maupun dalam pendidikan. ${ }^{4}$

Dari beberapa penelitian di atas, belum ada yang meneliti tentang Islam moderat dalam buku Pendidikan Agama Islam dan Budi Pekerti (selanjutnya disingkat PAIBP) untuk tingkat Sekolah Menengah Atas (SMA) kelas XI. Untuk mengisi kekosongan spot penelitian ini, artikel ini dihadirkan sebagai hasil penelitian pustaka. Untuk kepentingan ini, pembahasan dalam artikel ini dilakukan berdasarkan penelitian pustaka (library research), dengan mengkhususkan pada review pemikiran moderat para tokoh Islam dalam buku PAIBP SMA kelas XI, edisi tahun 2014 dan 2017 terbitan Kementerian Pendidikan dan Kebudayaan Republik Indonesia (Kemdikbud RI). Buku tersebut menjadi sumber data utama dalam penelitian ini. Selanjutnya penulis menganalisis data yang ada dengan analisis isi (content analysis).

Kehadiran artikel ini sangat penting mengingat belum banyak kajian yang mencoba fokus pada review pemikiran para tokoh Islam yang terdapat dalam buku PAIBP selama ini. Lebih-lebih, moderasi bergama kini menjadi konsen utama Kementerian Agama RI dan beberapa kementerian lainnya.

\section{Pemikiran Islam Moderat}

"Pemikiran moderat" dalam artikel ini merujuk pada pemikiran Islam moderat para tokoh Islam di buku PAIBP SMA kelas XI edisi tahun 2014 dan 2017. Sebelum membahas lebih jauh tentang pemikiran Islam moderat, ada baiknya terlebih dahulu dikupas secara lebih utuh tentang istilah "pemikiran" dan "Islam moderat" itu sendiri.

Kata "pemikiran" dalam Kamus Besar Bahasa Indonesia diartikan sebagai proses, cara, perbuatan memikir. ${ }^{5}$ Sementara dalam bahasa Inggris, "pemikiran" disebut thinking, yang berarti process of thinking; opinions about somethings;, opinion. ' Sedangkan kata "Islam" secara

\footnotetext{
4 Malia Fransisca, "Moderat Antar Umat, Organisasi dan Pendidikan," JUSPI (Jurnal Sejarah Peradaban Islam), Vol. 3, No. 1 (2019), 85.

5 Kamus Besar Bahasa Indonesia Daring, https://kbbi.kemdikbud.go.id/entri/ pemikiran.

${ }^{6}$ Kamus Oxford Learner's Dictionary Fourth Edition (UK: Oxford University Press, t.t.), 462 .

7 Longman, Dictionary of American English; New Edition (England: Pearson Education Limited, 2000), 451.
} 
etimologis berarti perlindungan, keamanan, konsiliasi dan perdamaian, pembebasan, penyerahan diri, dan ketaatan kepada Allah. ${ }^{8}$ Selanjutnya, kata "moderat" diartikan sebagai sebuah sikap dan tindakan yang memegang dan mau menerima atau memasuki wacana dialog peradaban, toleransi, dan kerukunan. ${ }^{9}$ Jadi, sikap moderat memiliki penekanan pada upaya menghargai dan menghormati keberadaan "yang lain" (the other), karena Islam adalah rahmatan li al-álamin (rahmat bagi seluruh masyarakat dunia). ${ }^{10}$

Islam moderat juga sering kali dimaknai Islam yang mempunyai prinsip menghargai perbedaan serta menghormati orang yang memiliki hidup yang tidak sama. ${ }^{11}$ Istilah Islam moderat seringkali juga dipopulerkan istilah lain yang memiliki makna yang sama, yaitu moderasi beragama. Dalam moderasi beragama, Islam tampil dengan corak yang santun, damai, tidak memaksa kehendak, tidak ekstrem kanan maupun kiri, serta mewarnai dakwah Islam. ${ }^{12}$ Tentu dalam konteks sikap moderat ini, Islam tetap dalam koridor amr ma'rüf naby munkar (menyuruh pada kebaikan dan melarang pada perbuatan mungkar) secara nyata di masyarakat. ${ }^{13}$

Sebagai upaya dalam moderasi bergama, Indonesia juga telah sempurna dengan hadirnya dua gagasan brilian, yakni gagasan Nahdlatul Ulama (NU) tentang "Islam Nusantara," dan gagasan Muhammadiyah tentang "Islam Berkemajuan." Kedua gagasan tersebut mampu menyuguhkan praktik dan pemahaman keagamaan yang ramah terhadap antarsesama, akomodatif terhadap kearifan lokal, dan kooperatif dengan keberadaan negara. ${ }^{14}$

\footnotetext{
8 Prasetiawati, "Menanamkan Islam Moderat."

${ }^{9}$ Miftahuddin, "Islam Moderat Konteks Indonesia."

${ }^{10}$ M. Hilaly Basya, "Menelusuri Artikulasi Islam Moderat di Indonesia," dalam http://www.madina-sk.com/index.php?option $=$ com, diakses tanggal 23 Juli 2009.

${ }^{11}$ Muttaqin dan Anwar, "Dinamika Islam Moderat,"23.

12 Ali Nurdin, "Model Moderasi Beragama berbasis Pesantren Salaf," Islamica: Jurnal Studi Keislaman, Vol. 14, No. 1 (2019), 88.

13 Mundzirin Yusuf, "Islam Berkemajuan dalam Perspektif Muhammadiyah," Islamica: Jurnal Studi Keislaman, Vol. 13, No. 1 (2019), 186.

14 Nur Syam dan Nawawi, "Islam Nusantara Berkemajuan sebagai Basis Moderasi Beragama di Indonesia," Islamica: Jurnal Studi Keislaman, Vol. 13, No. 2 (2019), 253.
} 
Kata "moderat" merupakan lawan dari kata "radikal." Radikal diartikan sebagai sikap yang diekspresikan melalui begitu bebasnya menilai orang lain sesuai dengan kehendaknya, mengkafirkan orang lain, atau bahkan mengusir kelompok lain yang berbeda pandangan dengannya. ${ }^{15}$ Radikal bisa tumbuh dengan mudah melalui berbagai jalur, antara lain jalur media sosial seperti Facebook. ${ }^{16}$

Bahkan radikalisme ini juga dapat tumbuh dengan pesat di bawah ketidaksadaran masyarakat Muslim dalam merespons modernisasi. ${ }^{17}$ Sampai di sini, maka yang dimaksud dengan pemikiran Islam moderat dalam artikel ini menjadi terang, yaitu pemikiran Islam yang menghargai orang lain yang tidak sepaham dalam batas koridor tertentu, di mana pemikiran yang demikian itu tergambar terang pada pemikiran sebelas tokoh Islam yang tersajikan dalam buku PAIBP SMA kelas XI edisi tahun 2014 dan 2017.

\section{Tema Kajian Mata Pelajaran PAI dan Budi Pekerti kelas XI}

Penelitian literatur ini mengkaji materi buku siswa mata pelajaran PAIBP SMA kelas XI tingkat Sekolah Menengah Atas edisi tahun 2014 dan 2017. Adapun kontributor naskah buku tersebut adalah Mustahdi dan Mustakim, dengan penelaah Yusuf A. Hasan dan Muh. Saerozi. Sedangkan penyelia penerbitannya adalah Pusat Kurikulum Perbukuan, Badan Penelitian dan Pengembangan (Balitbang), Kemdikbud RI. Sedangkan untuk buku siswa PAIBP SMA kelas XI edisi tahun 2017 ditulis oleh penulis yang sama, yakni Mustahdi dan Mustakim, dengan penelaah Asep Nursobah dan Ismail. Sebagai reviewer, tercantum nama Evi Zahara. Sementara penyelia penerbitannya yaitu Pusat Kurikulum dan Perbukuan, Balitbang, Kemendikbud RI. Kedua buku ini diterbitkan oleh Kemdikbud RI.

Sekilas, dari daftar isi kedua buku tersebut, terlihat beberapa perbedaan, antara lain pada item setiap bab nya. Dalam buku PAI dan Budi Pekerti Kelas XI tahun 2014, setiap bab terdiri dari

\footnotetext{
15 Slamet Muliono Redjosari, "Salafi dan Stigma Sesat-Radikal," Islamica: Jurnal Studi Keislaman, Vol. 13, No. 2 (2019), 311.

16 Eko Saputra, "Menelisik Dinamika Radikalisme Generasi Z Perempuan di Facebook," Islamica: Jurnal Studi Keislaman, Vol. 14, No. 1 (2019), 120.

17 Hamis Syafaq, "Radikalisme sebagai Blocking Factor Bagi Perkembangan Peradaban Islam Modern," Teosofi: Junal Tasawuf dan Pemikiran Islam, Vol. 4, No. 2 (2014), 452.
} 
Materi, Rangkuman dan Evaluasi. Sedangkan di buku PAIBP SMA kelas XI tahun 2017, di setiap bab terdapat beberapa item, yakni: Membuka Relung Hati, Mengkritisi Sekitar Kita, Memperkaya Khazanah, Materi, Menerapkan Akblak Mulia, Rangkuman, dan Evaluasi. Itemitem tersebut sama persis seperti yang terdapat pada buku PAIBP SMA kelas XI tahun 2014. Di dalam buku PAIBP 2014 tersebut, di setiap babnya, rupanya juga terdapat item Membuka Relung Hati, Mengkritisi Sekitar Kita, Memperkaya Khazanah, Materi, Menerapkan Perilaku Mulia, Rangkuman, dan Evaluasi. Perbedaan keduanya hanya terletak pada daftar isi saja.

Secara detail, dalam Buku PAIBP 2014 materi dipaparkan dalam 11 bab: (I) Al-Qur'ān sebagai Pedoman Hidup; (II) Hidup Nyaman dengan Perilaku Jujur; (III) Kepedulian Umat Islam terhadap Jenazah; (IV) Sampaikan dariku walau Satu Ayat; (V) Masa Kejayaan Islam yang Dinantikan Kembali; (VI) Membangun Bangsa Melalui Perilaku Taat, Kompetisi dalam Kebaikan, dan Etos Kerja; (VII) Rasul-rasul itu Kekasih Allah; (VIII) Hormati dan Sayangi Orang Tua dan Gurumu; (IX) Prinsip dan Praktik Ekonomi Islam; (X) Bangun dan Bangkitlah Wahai Pejuang Islam; (XI) Toleransi sebagai Alat Pemersatu Bangsa.

Demikian halnya dengan buku PAIBP 2017 yang memiliki jumlah bab yang sama persis, yakni terdiri dari XI bab, meskipun terdapat beberapa pergeseran materi: (I) Beriman kepada Kitabkitab Allah; (II) Berani Hidup Jujur; (III) Melaksanakan Pengurusan Jenazah; (IV) Saling Menasihati dalam Islam; (V) Masa Kejayaan Islam; (VI) Perilaku Taat, Kompetisi dalam Kebaikan, dan Etos Kerja; (VII) Rasul-rasul itu Kekasih Allah; (VIII) Menghormati dan Menyayangi Orang Tua dan Guru; (IX) Prinsip dan Praktik Ekonomi Islam; (X) Pembaruan Islam; (XI) Toleransi sebagai Alat Pemersatu Bangsa.

Dilihat dari esensi materinya pun kedua buku tersebut hampir sama persis, hanya beberapa redaksinya yang sedikit berbeda. Beberapa bab yang berubah redaksinya adalah bab I, II, III, IV, V, VI, VIII, dan X. Sedangkan bab yang redaksinya tetap dan sama persis ada tiga bab, yakni bab VII, IX, dan XI.

Dari 11 tema di buku PAIBP 2014 dan 2017, terdapat satu materi yang berhubungan erat dengan pemikiran Islam moderat dari pra tokoh Islam, yakni di bab X. Pada bab X buku PAIBP 2014 membahas dua sub tema yakni Islam Masa Modern; dan 
Tokoh-tokoh Pembaharuan Dunia Islam Masa Modern. Sedangkan di Buku PAIBP tahun 2017, bab X terdiri dari tiga subtema, yakni Islam Masa Modern; Tokoh-Tokoh Pembaharuan Islam pada Masa Modern; dan Pengaruh Gerakan Pembaharuan terhadap Perkembangan Islam di Indonesia.

Secara lebih detail, isi buku PAIBP tahun 2014 tergambar dari peta konsep di bawah ini.

Gambar 1:

Peta Konsep Bab X Buku PAIBP SMA Kelas XI edisi Tahun $2014^{18}$

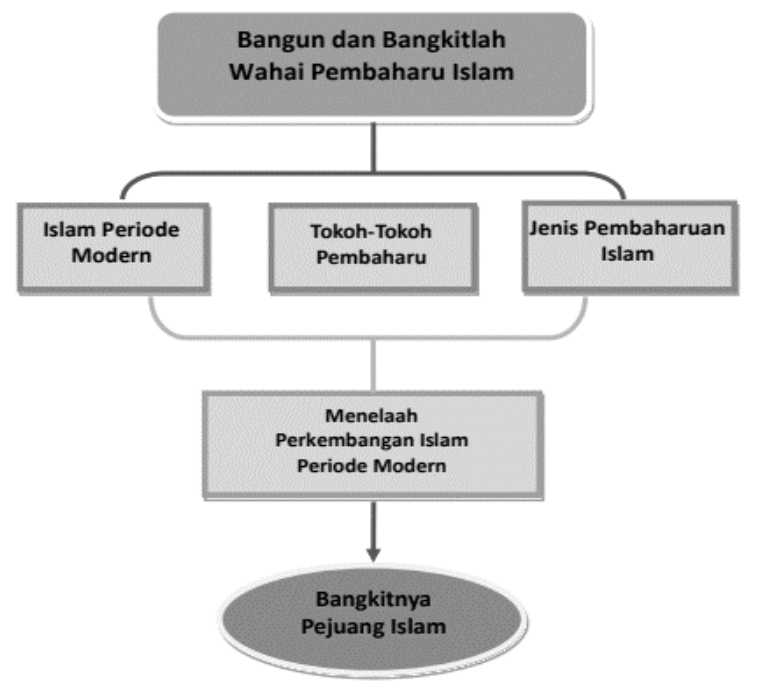

Dalam sub-bab Membuka Relung Hati, siswa diajak untuk menyadari fakta tentang begitu banyaknya jumlah penduduk Muslim di dunia ini, yang tentunya hal ini membawa pengaruh terhadap perilaku umat Islam. Sangat jelas terlihat munculnya beberapa macam kelompok Muslim yang menjadikan Islam berwarna-warni. Kondisi demikian tentunya tidak akan menjadi masalah selagi masih saling menghargai dan toleransi. Namun, jika setiap kelompok mengklaim bahwa kelompoknya yang paling benar, maka hal ini akan menjadi awal kehancuran umat Islam. Oleh karena itu, umat Islam harus tetap waspada dan terus belajar

${ }^{18}$ Kementerian Pendidikan dan Kebudayaan, Pendidikan Agama Islam dan Budi Pekerti Kelas XI (Jakarta: Kementerian Pendidikan dan Kebudayaan, 2014), 164. 
tentang Islam secara utuh (käffah) dan tetap menjaga keutuhan umat Nabi Muḥammad. ${ }^{19}$

Sub-bab selanjutnya di bab X ini adalah Mengkritisi Sekitar Kita. Dalam sub-bab ini, siswa diajak untuk mengkritisi dua kasus yang dilihat dari berbagai sudut pandang, yakni agama, sosial, budaya, dan lain sebagainya. Pertama, adalah kasus adanya kelompok umat Islam yang selama hidup di dunia ini hanya mementingkan urusan akhirat dan meninggalkan dunia. Mereka beranggapan bahwa memiliki harta-benda yang banyak, kedudukan yang tinggi, dan ilmu pengetahuan dunia adalah tidak perlu, karena hidup di dunia ini hanya sebentar dan sementara, sedangkan hidup di akhirat bersifat kekal dan abadi. Selain itu, banyak umat Islam yang menganut paham fatalisme, yaitu paham yang mengharuskan berserah diri kepada nasib dan tidak perlu berikhtiar karena hidup manusia dikuasai dan dikendalikan oleh nasib.

Kedua, kasus yang dikritisi adalah mengenai gairah generasi muda untuk mengkaji Islam tampak menggembirakan. Hal ini bisa dilihat dari maraknya kegiatan keislaman yang diikuti oleh pelajarpelajar dan remaja Islam. Namun demikian, antusiasme remaja Islam dalam melaksanakan kegiatan tidak dibarengi dengan semangat berkarya, baik dalam ilmu pengetahuan maupun yang lainnya. Akibatnya, perkembangan Islam hanya berhenti pada formalitas saja tetapi secara kualitas tidak nampak. ${ }^{20}$

Sub-bab berikutnya di bab X yang menjadi inti pembahasan dalam artikel ini, yaitu materi yang dikemas dalam tajuk Memperkaya Khazanah. Dalam buku PAIBP SMA kelas XI tahun 2014 terdapat dua materi, yakni "Islam Masa Modern (1800-sekarang)," dan "Tokoh-Tokoh Pembaharuan Dunia Islam Masa Modern."21 Sedangkan dalam Buku PAIBP SMA kelas XI tahun 2017 terdapat tiga sub-bab, yakni: "Islam Masa Modern (1800-sekarang)," "Tokoh-Tokoh Pembaharuan Dunia Islam Masa Modern," dan "Pengaruh Gerakan Pembaharuan terhadap Perkembangan Islam di Indonesia." Adapun peta konsep bab sepuluh buku PAIBP SMA kelas XI tahun 2017 adalah sebagai berikut:

\footnotetext{
${ }^{19}$ Ibid., 166.

20 Ibid., 167.

21 Ibid., 169.
} 


\section{Gambar 2: \\ Peta Konsep Bab X Buku PAIBP SMA Kelas XI \\ Edisi tahun $2017^{22}$}

Peta Konsep

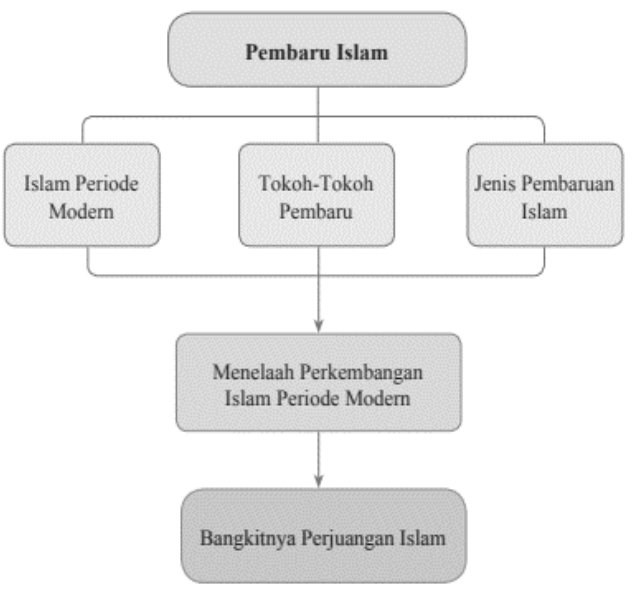

\section{Pemikiran Islam Moderat Para Tokoh Islam dalam Buku PAIBP SMA Kelas XI}

Buku PAIBP SMA kelas XI baik edisi tahun 2014 maupun 2017, keduanya memuat materi tentang pemikiran Islam moderat para tokoh pembaru Islam. Terdapat sepuluh tokoh pembaharu Islam di buku tahun 2014, yakni: Muhammad b. 'Abd al-Wahhāb, Shah Walī Allāh, Muhammad 'Alī Pāshā, al-Ṭahtāōì, Jamal al-Dīn al-Afghānī, Muḥammad 'Abduh, Rashīd Riḍā, Sayyid Aḥmad Khān, Sultan Mạ̣mūd II, dan Muḥammad Iqbāl. ${ }^{23}$ Sedangkan di Buku PAIBP SMA XI tahun 2017 juga terdiri dari sepuluh tokoh Islam, yakni Shah Wal̄i Allāh, Muhammad 'Alī Pāshā, al-Ṭahțāwī, Jamal al-Dīn al-Afghānī, Muḥammad 'Abduh, Rashīd Riḍā, Sayyid Aḥmad Khān, Sultan Maḥmūd II, Muḥammad Iquāl, dan Nemik $\mathrm{Kemal}^{24}$

Tabel 1:

${ }^{22}$ Kementerian Pendidikan dan Kebudayaan, Pendidikan Agama Islam dan Budi Pekerti Kelas XI (Jakarta: Kementerian Pendidikan dan Kebudayaan, 2017), 158.

${ }^{23}$ Kementerian Pendidikan dan Kebudayaan, Pendidikan Agama Islam (2014), 178.

${ }^{24}$ Kementerian Pendidikan dan Kebudayaan, Pendiddikan Agama Islam (2017), 175. 
Para Tokoh Islam di Buku PAIBP SMA Kelas XI

\begin{tabular}{|c|c|c|c|}
\hline \multicolumn{2}{|c|}{$\begin{array}{l}\text { Buku PAI dan Budi Pekerti } \\
\text { Kelas XI Edisi Tahun } 2014\end{array}$} & \multicolumn{2}{|c|}{$\begin{array}{l}\text { Buku PAI dan Budi Pekerti } \\
\text { Kelas XI Edisi Tahun } 2017\end{array}$} \\
\hline No & Nama Tokoh Islam & No & Nama Tokoh Islam \\
\hline 1. & $\begin{array}{l}\text { Muḥammad b. 'Abd al- } \\
\text { Wahhāb }\end{array}$ & 1. & Shah Walī Allāh \\
\hline 2. & Shah Walī Allāh & 2. & Muhammad 'Al̄̄ Pāshā \\
\hline 3. & Muḥammad 'Alī Pāshā & 3. & Al-Ṭahțāwī \\
\hline 4. & Al-Ṭahțāwī & 4. & Jamal al-Dīn al-Afghānī \\
\hline 5. & $\begin{array}{l}\text { Jamal al-Dīn al- } \\
\text { Afghānī }\end{array}$ & 5. & Muḥammad 'Abduh \\
\hline 6. & Muhammad 'Abduh & 6. & Rashīd Riḍā \\
\hline 7. & Rashīd Riḍā & 7. & Sayyid Aḥmad Khān \\
\hline 8. & Sayyid Aḥmad Khān & 8. & Sultan Mạ̣mūd II \\
\hline 9. & Sultan Maḥmūd II & 9. & Muḥammad Iqbāl \\
\hline 10. & Muḥammad Iqbāl & 10. & Namik Kemal \\
\hline
\end{tabular}

Muhammad b. 'Abd al-Wahhāb (1703-1787 M) yang lahir di 'Uyaynah, Nejd, Arab Saudi ini menjadi pencetus aliran Wahhābìyah yang sangat berpengaruh pada pemikiran pembaruan di abad ke-19. Pemikiran yang dicetuskan 'Abd al-Wahhāb kala itu bertujuan untuk memperbaiki kedudukan umat Islam. Pemikiran tersebut juga bukan sebagai reaksi terhadap suasana politik, melainkan lebih sebagai reaksi terhadap paham tauhid yang terdapat di kalangan umat Islam. Oleh karena itu, tidak mengherankan jika 'Abd al-Wahhāb berpendapat bahwa seorang Muslim yang meminta pertolongan pada selain Allah, misalnya pada seorang shaykh atau ulama adalah musyrik. Kegiatan syirik juga terlihat saat orang-orang Muslim menyebut nama nabi dalam 
doanya. Selanjutnya, syirik juga disematkan bagi mereka yang meminta syafaat serta bernadhar selain pada Allah. 'Abd alWahhāb juga mengkufurkan orang yang memperoleh pengetahuan selain dari al-Qur'ān, hadīth dan qiyās, tidak yakin qada dan qadrNya, dan mentakwil al-Qur'ān. Pemikiran 'Abd al-Wahhāb berikutnya yang tak kalah radikalnya adalah penegasan bahwa sumber ajaran Islam hanyalah al-Qur'ān dan Hadìth, sementara pendapat ulama bukan sumber ajaran Islam, dan seorang Muslim tidak boleh bertaklid pada ulama. ${ }^{25}$

Tokoh Islam yang kedua dalam buku PAIBP SMA kelas XI tahun 2014 adalah Shah Walī Allāh. Tokoh Islam yang dilahirkan di Delhi pada 21 Feubruari $1703 \mathrm{M}$ ini mempunyai pemikiran yang berbeda dengan Muhammad b. 'Abd al-Wahhāb. Pemikirannya berhaluan moderat, yang satu satu butirnya adalah mengubah sistem kekhalifahan menjadi sistem kerajaan; mengapresiasi kearifan lokal, di mana ia mengakui adat istiadat dan ajaran yang datang dari luar Islam masuk ke dalam cara keberagamaan umat Islam; demikian pula ia memperbolehkan penerjemahan al-Qur'ān ke dalam bahasa selain Arab. ${ }^{26}$

Tokoh Islam berikutnya adalah Muhammad 'Alī Pāshā yang lahir di Kawala, Yunani, pada 1765 M. Sebagaimana raja-raja Islam lainnya, 'Alī Pāshā mementingkan kemajuan militer dan kemajuan ekonomi. Ide atau gagasan 'Alī Pāshā yang sangat inovatif adalah perihal mendirikan sekolah-sekolah modern dan memasukkan ilmu-ilmu modern dan sains ke dalam kurikulumnya. ${ }^{27}$

Al-Ṭahțāwī merupakan tokoh pembaru selanjutnya yagn dibahas dalam buku tersebut. Tokoh dengan nama lengkap Rifā'ah Badwī Rāfi' al-Ṭahțāwī ini lahir pada 1801 M di Tahta, Mesir. Di antara beberapa pemikirannya tentang pembaruan Islam yaitu bahwa Islam tidak hanya soal akhirat, tetapi juga soal kehidupan dunia; seorang raja harus bermusyawarah dengan ulama dan kaum intelektual; ajaran Islam harus mengadopsi kehidupan di zaman modern; ulama harus menguasai ilmu pengetahuan modern;

\footnotetext{
25 Kementerian Pendidikan dan Kebudayaan, Pendidikan Agama Islam (2014), 170.

26 Ibid., 171.

${ }^{27}$ Ibid.
} 
emansipasi wanita perihal pendidikan; umat Islam tidak boleh statis, tetapi harus dinamis. ${ }^{28}$

Jamal al-Dīn al-Afghānī, tokoh pembaharu Islam yang lahir di Afghanistan pada $1939 \mathrm{M}$, adalah tokoh Islam kelima yang dimuat dalam buku ini. Beberapa pemikiran al-Afghānī tentang pembaruan Islam antara lain: tentang adanya banyak faktor yang menyebabkan kemunduran umat Islam; ajaran Islam harus dipahami dengan akal; pemerintahan harus bercorak demokratis; menjunjung asas musyawarah; dan agama dan politik tidak boleh dipisah. ${ }^{29}$

Setelah al-Afghānī, tokoh pembaharu Islam yang dibahas berikutnya adalah Muhammad 'Abduh. 'Abduh yang lahir di Mesir pada tahun $1849 \mathrm{M}$ itu mempunyai beragam ide pembaruan yang membawa dampak positif bagi pengembangan pemikiran Islam. Beberapa pemikirannya adalah: umat Uuslim boleh berijtihad; perlu menggunakan akal dan rasio dalam memahami ajaran Islam; dan konstitusi membatasi kekuasaan negara. ${ }^{30}$

Tokoh pembaru Islam berikutnya adalah Rashīd Riḍā. Ia adalah murid 'Abduh. Tokoh yang lahir di Lebanon pada 1865 ini memiliki beberapa pemikiran pembaharuan Islam, seperti: umat Islam harus aktif dan dinamis; tidak ada lagi pemikiran Jabarīyah; ayat dan bunyi hadīth boleh ditafsirkan dengan akal; jika ingin maju, harus menguasai sains dan teknologi; bid'ah dan khurafat merusak ajaran Islam; hukum Allah untuk menciptakan kebahagiaan dunia akhirat; membolehkan pemerintahan khalifah; penguasa agama dan politik adalah khalifah; Khalifah harus menerapkan hukum Islam sesuai dengan perkembangan dan tuntutan zaman. ${ }^{31}$

Bandingkan dengan pemikiran tokoh pembaru Islam yang dibahas berikutnya, yaitu Sayyid Aḥmad Khān yang lahir di Delhi pada tahun 1817 M. Pemikirannya tentang pembaruan Islam tidak jauh berbeda dengan para tokoh Islam sebelumnya. Ia menyatakan bahwa umat Islam mengalami kemunduran karena abai terhadap dinamika zaman; manusia bebas berkehendak sesuai dengan akal dan berbuat sesuai dengan sunatullāh; al-Qur'ān dan hạàith adalah sumber ajaran Islam; umat Islam tidak boleh taklid; ijtihad sangat

\footnotetext{
${ }^{28}$ Ibid., 172.

${ }^{29}$ Ibid., 173.

${ }^{30}$ Ibid., 174.

${ }^{31}$ Ibid., 176.
} 
diutamakan; pendidikan adalah hal terpenting untuk mengubah mindset umat Islam. ${ }^{32}$

Sultan Mahmūd II juga mrupakan tokoh penting pembaru Islam yang diperkenalkan kepada siswa SMA kelas XI melaui buku PAIBP. Sultan Mạ̣mūd II lahir pada tahun 1785 M. Pemikiran Islam moderatnya menyatakan bahwa pemerintah harus demokratis; sultan adalah manusia biasa, bukan orang suci dan tidak boleh dikultuskan; dimasukkannya kurikulum umum ke dalam lembaga-lembaga pendidikan madrasah; Sultan Maḥmūd II juga mendirikan sekolah Maktebi Ma'arif dan Maktebi Ulumi Edebiyet; dan ia juga mendukung penuh pendirian sekolah kedokteran, militer, dan teknik. ${ }^{33}$

Tokoh Islam yang terakhir adalah Muhammad Iqbāl. Ia terlahir di Sialkot pada tahun 1876 M. Pemikiran Islamya yang terkenal adalah pembukaan kembali pintu ijtihad seluas-luasnya; Islam dipandang harus dinamis; umat Islam tidak boleh statis; kejumudan pikir menyebabkan kemunduran umat Islam; dinamisasi dalam hukum Islam; sains dan teknologi harus dimiliki umat Islam; dan redefinisi zuhud. ${ }^{34}$

Selanjutnya, bab sepuluh pada buku PAI dan Budi Pekerti kelas XI tahun 2017 agak sedikit berbeda dengan tahun 2014. Jika di buku tahun 2014 terdapat tokoh Islam 'Abd al-Wahhāb, maka di buku tahun 2017 tidak lagi terdapat tokoh ini, dan digantikan oleh nama Namik Kemal (1840-1888 M). Kemal tidak dibahas di buku PAIBP SMA kelas XI tahun 2014. Inilah yang dimaksudkan dengan pergeseran materi dari buku PAIBP SMA kelas XI tahun 2014 dan 2017.

Dalam buku PAIBP tahun 2017, disebutkan bahwa Kemal memiliki jiwa Islam yang baik. Ia menerima berbagai ide dari Barat dengan memodifikasinya secara selektif hingga sesuai dengan ajaran Islam. Pemikiran-pemikirannya antara lain: negara harus melindungi hak-hak politik rakyat; corak kepemimpinan khulafä' alräshidin adalah kepemimpinan demokrasi; khalifah harus meng-

\footnotetext{
${ }^{32}$ Ibid., 177.

${ }^{33}$ Ibid., 178.

34 Ibid., 179.
} 
utamakan al-maslahat al-'ammah (kebaikan umum); sharī'ah Islam tidak boleh dilanggar, oleh pimpinan negara sekalipun. ${ }^{35}$

Dari paparan data di atas sangat jelas terlihat bahwa dari kesebelas pemikiran para tokoh Islam, kebanyakan dari mereka memiliki pemikiran Islam moderat. Sembilan tokoh Islam yang memiliki pemikiran Islam moderat adalah Shah Walī Allāh, 'Alī Pāshā, al-Ṭahțāwī, al-Afghānī, 'Abduh, Rị̣ā, Aḥmad Khān, Sultan Mahmūd II, dan Iqbāl. ${ }^{36}$ Sedangkan di PAIBP SMA kelas XI tahun 2017 juga terdiri dari sepuluh tokoh Islam, yakni Shah Wal̄ Allāh, 'Alī Pāshā, al-Ṭahțāwī, al-Afghānī, 'Abduh, Riḍā, Aḥmad Khān, Sultan Mạ̣mūd II, Iqbāl, dan Namik Kemal. Moderasi pemikiran keislaman kesepuluh tokoh Islam tersebut ini terlihat jelas dari hasil buah pikirnya yang dipopulerkan dan dijadikan kebijakan di masanya.

Secara general, mereka menyepakati bahwa Islam adalah agama yang terbuka dan rahmatan li al-älamin. Mereka membuka peluang pintu ijtihad untuk pembaruan pemikiran dalam Islam, bahkan terhadap hal yang belum pernah dilakukan oleh para tokoh Islam di zaman sebelumnya.

Hanya satu tokoh yang pemikirannya berbeda dengan para tokoh Islam yang lainnya, yakni 'Abd al-Wahhāb. Pemikirannya tentang tauhid memang agak cenderung strict dan keras. Pemikiran kerasnya ini kurang bisa menghormati keberadaan yang lain. Hal ini bisa terlihat dari penyataannya bahwa menyebut nama nabi atau shaykh sebagai perantara doa adalah syirik. Meminta syafaat dan bernadhar selain kepada Allah juga dihukumi syirik. Demikian pula status kufur diberikan kepada Muslim yang telah memperoleh pengetahuan selain dari al-Qur'ān, hadìth dan qiyās. Pemikiran radikal 'Abd al-Wahhāb lainnya juga terlihat dari pernyataannya bahwa mentakwil al-Qur'ān adalah kufur. Selanjutnya, hanyalah alQur'ān dan hadīth yang merupakan sumber asli ajaran Islam, sementara pendapat ulama bukan merupakan sumber ajaran Islam.

Bahkan, ada satu pemikiran 'Abd al-Wahhāb yang sempat dihapus oleh pihak penerbit buku tersebut, yakni "menyembah

\footnotetext{
35 Kementerian Pendidikan dan Kebudayaan, Pendidikan Agama Islam (2017), 175.

36 Kementerian Pendidikan dan Kebudayaan, Pendidikan Agama Islam (2014), 169-178.
} 
selain Allah adalah kafir, dan orang kafir boleh dibunuh." ${ }^{37}$ Jelas pernyataan ini sangat berbahaya. Apalagi jika diberikan atau disampaikan pada siswa dengan keterangan kontekstual yang kurang memadai. Alih-alih bisa menginternalisasi nilai-nilai Islam moderat pada siswa, malah bisa terjadi yang sebaliknya, yaitu menubuhkan benih radikalisme dalam pikiran dan sikap siswa. Lebih-lebih materi ini di bawah bab yang berjudul Bangun dan Bangkitlah Wahai Pejuang Islam. Kondisi tersebut tentu bukanlah hal yang diinginkan oleh lembaga pendidikan. Pemerintah melalui lembaga pendidikan berupaya keras untuk menginternaslisasi prinsip-prinsip Islam moderat pada para civitas akademika di setiap lembaga pendidikan yang ada di Indonesia.

Karena pertimbangan pemikiran radikal atau tidak moderat ini, maka dalam buku PAIBP SMA kelas XI tahun 2017, tokoh Islam 'Abd al-Wahhāb ini tidak disertakan lagi. Di buku tahun 2017, nama 'Abd al-Wahhāb diganti dengan nama tokoh Islam lainnya, yakni Namik Kemal. Kemal adalah tokoh Islam yang mempunyai gaya berpikir dan bersikap Islam moderat. Penggantian nama tersebut dirasa perlu dilakukan oleh pemerintah, karena sekali lagi, pemerintah menginginkan lembaga pendidikan menjadi suatu media dan wadah yang bisa mencetak para civitas akademika sebagai warga negara yang berpikiran Islam moderat.

\section{Penutup}

Islam moderat adalah Islam yang menekankan sikap menghargai dan menghormati keberadaan "yang lain" (the other) dan rabmatan li al'älamin (rahmat bagi seluruh masyarakat dunia). Islam mempunyai prinsip menghargai perbedaan serta menghormati orang yang memiliki cara hidup yang tidak sama. Pemerintah telah berupaya untuk menanamkan Islam moderat kepada para siswa, yakni melalui materi yang disampaikan dalam buku siswa mata pelajaran PAIBP SMA kelas XI. Penelitian ini mencoba untuk mereview pemikiran Islam moderat para tokoh Islam yang dipaparkan dalam buku tersebut, baik yang diterbitkan pada tahun 2014 maupun 2017.

Hasil penelitian ini menyatakan bahwa terdapat sepuluh tokoh Islam dan pemikirannya di buku PAIBP SMA keals XI tahun 2014.

37 Talkah et al., Analisis Buku Pendidikan Agama Islam dan Budi Pekerti kelas XI (Makalah--Program Pascasarjana UIN Sunan Ampel Surabaya, Maret 2020), 3. 
Dari kesepuluh tokoh tersebut terdapat satu tokoh Islam, yakni Muhammad b. 'Abd al-Wahhāb, yang pemikirannya tidak moderat, akan tetapi justru cenderung radikal. Sedangkan sembilan tokoh Islam yang lainnya berpikiran Islam moderat. Sehingga pada edisi revisi, yakni pada buku PAIBP kelas XI tahun 2017, nama 'Abd alWahhāb ini tidak dicantumkan lagi dan diganti dengan nama tokoh Islam moderat lainnya, Namik Kemal. Dengan demikian, pada buku PAIBP SMA kelas XI edisi tahun 2017, kesepuluh tokoh pembaru Islam yang dipaparkan semuanya mempunyai pemikiran Islam moderat.

Buku PAIBP SMA kelas XI tahun 2014 sudah seharusnya tidak dipakai lagi di sekolah, dan edisi revisinya pada tahun 2017. Terkait hal ini, harus ada himbaun dan penjelasan dari pemerintah secara tegas. Mengingat penelitian ini masih berkutat pada pemikiran Islam moderat yang ada di dalam buku PAIBP SMA kelas XI saja, belum mencakup kelas X dan XII, maka sebagai rekomendasi bagi pembaca dan peneliti lain, agar dapat menyempurnakan penelitian dalam artikel ini dengan melakukan penelitian pada pemikiran Islam moderat di buku PAIBP di kelas lain baik di level Sekolah Menengah Atas, Sekolah Menengah Pertama, atau Sekolah Dasar. Penelitian yang serupa juga perlu dikembangkan tidak hanya di lingkungan sekolah, tetapi juga hendaknya merambah ke lingkungan madrasah, baik di tingkat Madrasah Ibtidaiyah (MI), Madrasah Tsanawiyah (MTs), maupun Madrasah Aliyah (MA).

\section{Daftar Rujukan}

Badan Pengembangan dan Pembinaan Bahasa Kemdikbud. Kamus Besar Bahasa Indonesia Daring, https://kbbi.kemdikbud.go.id/ entri/pemikiran.

Basya, M. Hilaly. "Menelusuri Artikulasi Islam Moderat di Indonesia," dalam http://www.madina-sk.com/ index.php? option=com, diakses tanggal 23 Juli 2009.

Fransisca, Malia. "Moderat Antar Umat, Organisasi dan Pendidikan," JUSPI (Jurnal Sejarah Peradaban Islam), Vol. 3, No. 1 (2019), 85.

Kementerian Pendidikan dan Kebudayaan. Pendidikan Agama Islam dan Budi Pekerti Kelas XI. Jakarta: Kementerian Pendidikan dan Kebudayaan, 2014.

-----. Pendidikan Agama Islam dan Budi Pekerti Kelas XI. Jakarta: Kementerian Pendidikan dan Kebudayaan, 2017. 
Longman. Dictionary of American English New Edition. England: Pearson Education Limited, 2000.

Miftahuddin. "Islam Moderat Konteks Indonesia dalam Perspektif Historis," MOZAIK, Vol. 5, No. 1, 2010.

Muttaqin, Ahmad Ihwanul dan Syaiful Anwar. "Dinamika Islam Moderat, Studi Atas Peran LP. Ma'arif NU Lumajang dalam Mengatasi Gerakan Radikal," Tarbiyatuna: Jurnal Pendidikan Islam, Vol. 12, No. 1, 2019.

Nurdin, Ali. "Model Moderasi Beragama berbasis Pesantren Salaf," Islamica: Jurnal Studi Keislaman, Vol. 14, No. 1, 2019.

Oxford Learner's Dictionary Fourth Edition. UK: Oxford University Press, t.t.

Prasetyawati, Eka. "Menanamkan Islam Moderat: Upaya Menanggulangi Radikalisme di Indonesia," Fikri, Vol. 2, No. 2 (2017.

Redjosari, Slamet Muliono. "Salafi dan Stigma Sesat-Radikal," Islamica: Jurnal Studi Keislaman, Vol. 13, No. 2, 2019.

Saputra, Eko. "Menelisik Dinamika Radikalisme Generasi Z Perempuan di Facebook," Islamica: Jurnal Studi Keislaman, Vol. 14, No. 1, 2019.

Syafaq, Hamis. "Radikalisme sebagai Blocking Factor Bagi Perkembangan Peradaban Islam Modern," Teosofi: Junal Tasawuf dan Pemikiran Islam, Vol. 4, No. 2, 2014.

Syam, Nur dan Nawawi. "Islam Nusantara Berkemajuan sebagai Basis Moderasi Beragama di Indonesia," Islamica: Jurnal Studi Keislaman, Vol. 13, No. 2, 2019.

Talkah et al. Analisis Buku Pendidikan Agama Islam dan Budi Pekerti kelas XI. Makalah--Program Pascasarjana UIN Sunan Ampel Surabaya, Maret 2020.

Yusuf, Mundzirin. "Islam Berkemajuan dalam Perspektif Muhammadiyah," Islamica: Jurnal Studi Keislaman, Vol. 13, No. 1, 2019. 